University of Nebraska - Lincoln

DigitalCommons@University of Nebraska - Lincoln

Faculty Publications from the Harold W. Manter Laboratory of Parasitology

2-1994

\title{
Echinococcus granulosus (Taeniidae) and Autochthonous Echinococcosis in a North American Horse
}

Eric P. Hoberg

United States Department of Agriculture, Agricultural Research Service, ehoberg@ggpl.arsusda.gov

S. Miller

Maryland Department of Agriculture, Animal Health Laboratory

M. A. Brown

Middletown, Maryland

Follow this and additional works at: https://digitalcommons.unl.edu/parasitologyfacpubs

Part of the Parasitology Commons

Hoberg, Eric P.; Miller, S.; and Brown, M. A., "Echinococcus granulosus (Taeniidae) and Autochthonous Echinococcosis in a North American Horse" (1994). Faculty Publications from the Harold W. Manter Laboratory of Parasitology. 604.

https://digitalcommons.unl.edu/parasitologyfacpubs/604

This Article is brought to you for free and open access by the Parasitology, Harold W. Manter Laboratory of at DigitalCommons@University of Nebraska - Lincoln. It has been accepted for inclusion in Faculty Publications from the Harold W. Manter Laboratory of Parasitology by an authorized administrator of DigitalCommons@University of Nebraska - Lincoln. 


\section{RESEARCH NOTES}

J. Parasitol., 80(1), 1994, p. 141-144

(C) American Society of Parasitologists 1994

\section{Echinococcus granulosus (Taeniidae) and Autochthonous Echinococcosis in a North American Horse}

E. P. Hoberg, S. Miller*, and M. A. Brownt, United States Department of Agriculture, Agricultural Research Service, Biosystematic Parasitology Laboratory, BARC East No. 1180, 10300 Baltimore Avenue, Beltsville, Maryland 20705; *Maryland Department of Agriculture, Animal Health Laboratory, P.O. Box 1234, Montevue Lane, Frederick, Maryland 21702; and †1631 Mountain Church Road, Middletown, Maryland 21769

ABSTRACT: We report the first documented case of autochthonous echinococcosis in a horse of North American origin. Three fully mature and viable unilocular hydatid cysts of Echinococcus granulosus (Batsch, 1786) were an incidental finding at necropsy in the liver of a 14-yr-old gelding thoroughbred that had been foaled in Virginia and raised in Maryland. Protoscolices were armed with 2 rows of 28-37 rostellar hooks; small hooks measured 23-30 $\mu \mathrm{m}$; large hooks measured 26-33 $\mu \mathrm{m}$. Morphologically, these were compatible with rostellar armature considered typical for the equine strain of $E$. granulosus currently known primarily from the United Kingdom. This horse had a history of fox hunting, and huntsman at some premises in the region are known to feed uncooked viscera from horse carcasses to their dogs. These factors would support maintenance of infection by $E$. granulosus in equine hosts. The putative introduction and establishment of the equine strain of $E$. granulosus and recognition of endemic equine hydatid disease in the eastern U.S.A. warrants monitoring and additional investigation.

A 14-yr-old thoroughbred gelding, foaled in Virginia and raised in Maryland, was referred to the Animal Health Laboratory of the Maryland Department of Agriculture for evaluation of mild neurological signs. Subsequently, it was considered unsafe to ride and was killed. At necropsy, no gross lesion was evident, except for the incidental finding of 3 cysts and numerous white foci visible, beneath Glisson's capsule, at the hepatic surface. Material was fixed in buffered $10 \%$ formalin for later detailed study. Histological sections stained in hematoxylin and eosin revealed the focal lesions, $2-3 \mathrm{~mm}$ in diameter, to be eosinophilic/lymphocytic granulomas of undetermined etiology.

Gross examination and dissection of the cysts confirmed their identification as typical unilocular, fluid-filled metacestodes of the taeniid cestode Echinococcus granulosus (Batsch, 1786). The cysts were ovoid, lacked internal septa, and measured $3.5-5.0 \mathrm{~cm}$ in greater diameter. Numerous brood capsules were attached to the germinal membrane or detached and floating in the cyst fluid and contained typical protoscolices that appeared to be viable (Figs. 1, 2) (Williams and Sweatman, 1963; Thompson and Smyth, 1975; Kumaratilake et al., 1986). Rostellar armature consisted of $28-37$ hooks $(\bar{x}=33.27 \pm 2.03$; $\mathrm{n}$ $=30$ scolices) usually arranged in 2 rows (in 1 specimen there was a single minuscule hook in an incomplete third row); large hooks measured 26-33 $\mu \mathrm{m}$ long $(\bar{x}=30.1 \pm 1.097 ; \mathrm{n}=216$ hooks); small hooks measured 23-30 $\mu \mathrm{m}$ long ( $\bar{x}$ $=26.8 \pm 1.46 ; n=216$ hooks) (Figs. 3, 4). Specimens were deposited in the U.S. National Parasite Collection, USDA, ARS, Biosystematic Parasitology Laboratory, Beltsville, Maryland (USNM No. 83058).

Recognition of the larval stage of $E$. granulosus in the intermediate host is based on a combination of morphological characters, epidemiological data, and biological features (Williams and Sweatman, 1963; Rausch, 1967, 1986; Kumaratilake et al., 1986; Thompson and Lymbery, 1988). Originally recognized as a subspecies, Echinococcus granulosus equinus Williams and Sweatman, 1963, occurring in Great Britain, the cestode whose larval stage develops in horses currently is recognized only as a biological strain (Thompson and Lymbery, 1988, 1990). In horses, larvae usually are found as multiple unilocular hydatids that occur in the liver (rarely in the lungs) and the dimensions of the rostellar hooks on infective protoscolices are distinct (Williams and Sweatman, 1963; Kumaratilake et al., 1986). Hydatid cysts of equine origin can be distinguished unequivocally, and the present material clearly is within the ranges established previously for the length of large (range $=26-35, \bar{x}=30.4$ $\mu \mathrm{m} ; \bar{x}=29-31 \mu \mathrm{m})$ and small hooks $(21-31, \bar{x}$ $=27.8 \mu \mathrm{m} ; \bar{x}=26-28 \mu \mathrm{m}$ ) (Williams and Sweatman, 1963; Kumaratilake et al., 1986). However, identity of the present specimens could be confounded by recent studies that indicate that the structure of the rostellar hooks may be influenced 

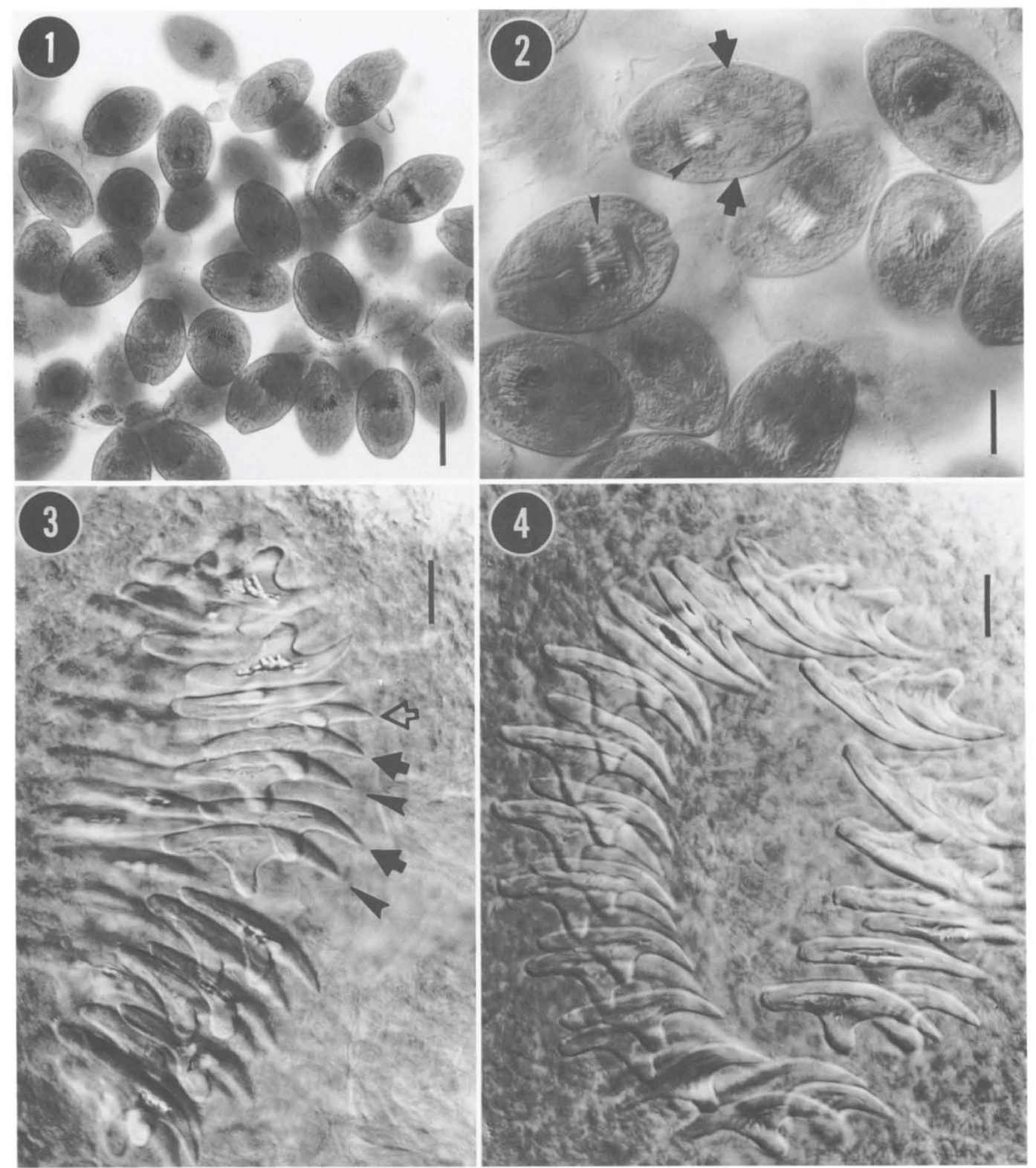

Figures 1-4. Echinococcus granulosus collected from the liver of an equine host in Maryland. 1. Protoscolices from several brood capsules collected from a unilocular cyst (scale bar $=100 \mu \mathrm{m}$ ). 2. Protoscolices from a single brood capsule, note typical suckers (arrows) and rostellar hooks (pointers) (scale bar $=50 \mu \mathrm{m}$ ). 3. Rostellar armature on a protoscolex with 35 hooks (not all visible), showing form of large (pointers) and small hooks (solid arrows) distributed in 2 primary rows and single minuscule hook (open arrow) in an incomplete third row $($ scale bar $=10 \mu \mathrm{m})$. 4. Rostellar hooks from a protoscolex with 34 hooks, showing typical structure and distribution in 2 rows (scale bar $=10 \mu \mathrm{m})$.

by the intermediate host (Hobbs et al., 1990; Constantine et al., 1993). This phenomenon, yet to be evaluated for the equine strain, could have applications for potential epidemiological surveys (Constantine et al., 1993).
Equine hydatid disease is apparently rare in North America and there have only been 5 previous records of $E$. granulosus in horses: in Washington state (Cordy and Eastlick, 1951), Illinois (Gelberg et al., 1984), New York (Foley 
and Georgi, 1986), North Carolina (Binhazim et al., 1992), and Kentucky (Rezabek et al., 1993). In contrast to the present report, all of these horses had been imported from Ireland or the United Kingdom and were considered to have been infected prior to arrival in North America. There is no previous record of autochthonous echinococcosis in an equine host of North American origin.

Several potential explanations must be considered to explain hydatid cysts of autochthonous origin in an equine host. Two major biotypes of $E$. granulosus currently are recognized in North America (Rausch, 1967, 1986; Bryan and Schantz, 1989; Thompson and Lymbery, 1990). A northern (sylvatic) biotype (without recognized strains), with cervid intermediate and canine definitive hosts, was historically endemic in the Holarctic region at higher northern latitudes (in North America mainly above ca. lat. $48^{\circ} \mathrm{N}$; i.e., the southern limit of the boreal forest). A European or domestic biotype (with a number of recognized strains and cosmopolitan in distribution), circulating in a synanthropic cycle with domestic ungulates (sheep, swine, and cattle) and dogs was introduced with the transport of domestic stock to North America and became widespread by the late 19 th century. Currently the European biotype is considered to be absent from the eastern seaboard, although it had been established in swine and cattle in the earlier part of this century and was present in Maryland (Rausch, 1967). The 2 biotypes are largely allopatric and are well differentiated ecologically and biologically (Rausch, 1967). There is a very low susceptibility for reciprocal infection by strains of $\boldsymbol{E}$. granulosus in sheep and horses (Thompson and Smyth, 1975; Thompson, 1977; Thompson and Lymbery, 1988) and no precedent for cross infection to domestic ungulates by the northern biotype (Rausch, 1967, 1986). Consequently, involvement of equine hosts in either the synanthropic or sylvatic cycle may be discounted.

The low probability of a domestic or sylvatic cycle for $E$. granulosus in north-central Maryland suggests that equine echinococcosis of British origin has become established in North America. In Britain, hydatid disease is widespread in horses and transmission is associated with fox hunting where dogs belonging to hunting packs are the primary definitive hosts (Thompson and Smyth, 1975). Transmission was found to be enhanced by the feeding of raw uninspected viscera from infected horses to hunting dogs, resulting in a dramatic increase in prevalence (exceeding $60 \%$ in horses from some regions) during the 1960 s and 1970s. The potential for introduction of the equine strain of this parasite into North America had been suggested previously by its broad occurrence in the United Kingdom (Thompson and Smyth, 1975) and a history of export of horses (and hounds) from this area (Kumaratilake et al., 1986; Binhazim et al., 1992). In North America, although the possibility for widespread occurrence exists, practices associated with fox hunting were considered to be a limiting factor for the distribution and prevalence of infection by this cestode (Binhazim et al., 1992). The potential has also existed for the importation of this cestode with hunting dogs brought into the U.S.A. from the United Kingdom; hounds from the latter region have been used in some local hunts in Maryland and southern Pennsylvania.

In regard to the current case, the host was foaled in northern Virginia by 1978 , brought to Maryland at the age of 8 or $9 \mathrm{mo}$, and raised in proximity to fox hounds and used in fox hunting in northern Maryland. Consequently, it is certain that infection by $E$. granulosus occurred in this region. At least some of the traditional hunting establishments in northern Maryland and southern Pennsylvania have a practice of feeding raw viscera and meat from horses to hounds. Thus, potentially a pattern similar to that demonstrated in Great Britain has been established (Thompson and Smyth, 1975). Indeed, the practice of feeding uncooked offal to dogs may be increasing due to the high costs involved in disposing of horse carcasses; additional cases could be expected.

Risk to public health associated with the equine strain would be influenced by the apparent low infectivity in humans, relatively limited direct contact between dogs and handlers, and a slower rate of development for the larval parasite (Thompson and Smyth, 1975). The present case may be epidemiologically significant and should warrant investigation into the possible patterns of transmission for $E$. granulosus among equine hosts in the eastern U.S.A.

We thank Robert L. Rausch for sharing his ideas on $E$. granulosus in North America and providing a critical review. Linda Mansfield re- 
viewed the manuscript and commented on fox hunting in the region.

\section{LITERATURE CITED}

Binhazim, A. A., B. G. HaRmon, E. L. Roberson, AND M. BOERNER. 1992. Hydatid disease in a horse. Journal of the American Veterinary Medical Association 200: 958-960.

Bryan, R. T., AND P. M. SChantz. 1989. Echinococcosis (hydatid disease). Journal of the American Veterinary Medical Association 195: 12141217.

Constantine, C. C., R. C. A. Thompson, D. J. Jenkins, R. P. HOBBs, AND A. J. LyMbery. 1993. Morphological characterization of adult Echinococcus granulosus as a means of determining transmission patterns. Journal of Parasitology 79: 57-61.

CORDY, D. R. AND M. G. EASTLICK. 1951. A report of Echinococcus granulosus in a horse in the State of Washington. Journal of Parasitology 37: 318.

Foley, G. L., AND M. GeORGI. 1986. Hydatidosis in a horse. Veterinary Pathology 23: 646-647.

Gelberg, H. B., K. S. TodD, W. M. DucKett, AND R. K. SANECKI. 1984. Hydatid disease in a horse. Journal of the American Veterinary Medical Association 184: 342-343.

HobBs, R. P., A. J. LyMBeRY, AND R. C. A. THOMPSON. 1990. Rostellar hook morphology of Echinococcus granulosus (Batsch, 1786) from natural and experimental Australian hosts, and its implications for strain recognition. Parasitology 101: 273281.

Kumaratilake, L. M., R. C. A. Thompson, and J. ECKERT. 1986. Echinococcus granulosus of equine origin from different countries possess uniform morphological characteristics. International Journal for Parasitology 16: 529-540.

RAUSCH, R. L. 1967. On the ecology and distribution of Echinococcus spp. (Cestoda: Taeniidae), and characteristics of their development in the intermediate host. Annales Parasitologie Humaine et Compareé 42: 19-63.

- 1986. Life-cycle patterns and geographic distribution of Echinococcus species. In The biology of Echinococcus and hydatid diseases, R. C. A. Thompson (ed.). George Allen and Unwin Publishers, London, p. 44-80.

RezabeK, G. B., R. C. Giles, AND E. T. Lyons. 1993. Echinococcus granulosus hydatid cysts in the livers of two horses. Journal of Veterinary Diagnostics Investigations 5: 122-125.

Thompson, R. C. A. 1977. Growth, segmentation and maturation of the British horse and sheep strains of Echinococcus granulosus in dogs. International Journal for Parasitology 7: 281-285.

, AND A. J. LyMBery. 1988. The nature, extent and significance of variation within the genus Echinococcus. Advances in Parasitology 27: 209258.

, AND - 1990. Echinococcus: Biology and strain variation. International Journal for Parasitology 20: $457-470$.

, AND J. D. SMYTH. 1975. Equine hydatidosis: A review of the current status in Great Britain and the results of an epidemiological survey. Veterinary Parasitology 1: 107-127.

Williams, R. J., And G. K. Sweatman. 1963. On the transmission, biology and morphology of Echinococcus granulosus equinus, a new subspecies of hydatid tapeworm in horses in Great Britain. Parasitology 53: 391-407. 